The patient, who had always been optimistic, said " the sight was more useful than before."

On September 7, 1937, the patient was found to have a complete cataract. The projection and perception of light were good. Operation for the removal of the lens was suggested.

September 20,1937, extraction of the lens. The operation was uneventful, and a week after the extraction fundus details could be seen. And the hole was seen to be healed. A report was received from the patient's doctor that with a high hypermetropic lens, the patient had seen $6 / 36$.

May, 1938. As the sight had again diminished, it was decided to do a needling. The patient returned to his home, and reported again.

September 27, 1938. At this examination with a +8.0 D.Sph. the patient saw $6 / 24$, could tell the time of a plain marked wrist watch, and read J.12. c. 11.0 D.Sph.

\title{
Summary
}

May, 1934. 1. Puncture operation to allow retina to flatten. 2. Operation for closure of tear.

September, 193\%. Extraction of lens.

May, 1938. Needling of the capsule.

September 9, 1938. Visual result. $6 / 24=\mathrm{J} .12$.

\section{THE AETIOLOGY OF TRACHOMA}

\author{
BY \\ F. H. STEWART, M.D. \\ LATELY PATHOLOGIST TO THE MEMORIAL OPHTHALMIC \\ LABORATORY, GIZA
}

THE parasitic cause of trachoma (Chlamydozoon trachomatis) was discovered in the year 1907 in the two widely separate regions of Java and East Prussia (Halberstaedter and Prowazek; v. Greeff, Frosch and Clausen). It was soon confirmed from Austria and since then has been found in all parts of the world.

The parasite passes through two stages, one free or extracellular in the secretion of trachomatous eyelids and the second intracellular in the epithelium of the conjunctiva. The free stage, or free initial body of Lindner, is a polymorph organism (Fig. 1).

Bipolar bacilli, small diplococci and single micrococci have been described. The bipolar bacillus is the only form which can be recognized with certainty if there is secondary bacterial infection, 
Figures.-Drawn to scale with an Abbé camera from slides stained with Giemsa, Figs. 1 and 2 are $\times 3000$, Figs. 3, 4 and 5 are $\times 1500$.

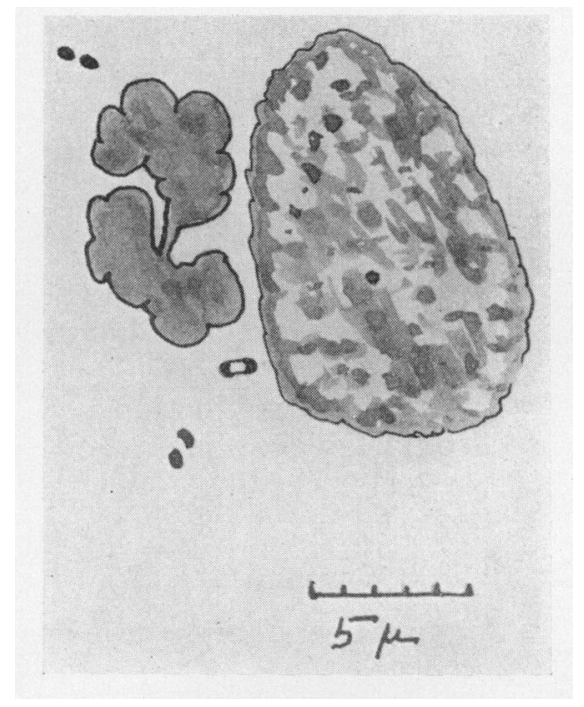

FIG. 1.

Three free initial bodies in the secretion of a trachomatous conjunctiva with two nuclei.

since the other forms differ from common conjunctival bacteria only in size. The bipolar bacillus measures $0.75-1.0 \mu \times 0.5 \mu$ and the diplococci about $1.5 \mu$ the pair. In the second stage the initial body having entered the cytoplasm of an epithelial cell, becomes rounded or oval in shape and increases in size (Figs. 2 and 3): Several initial bodies may coalesce and finally a hemispherical or kidney-shaped mass is formed which lies close to the nucleus and measures from 3 to $13 \mu$. This is the Prowazek-Halberstaedter body or P.K. (Fig. 5). Initial bodies both free and intracellular stain dark blue with Giemsa. When this blue inclusion body has reached a certain size, granules of $0.25 \mu$ appear in its centre and increase in number until they occupy the whole body except a thin outer shell. These elementary granules stain red with Giemsa. The inclusion body may rupture or its contents may be set free by the break up of the containing cell.

While inclusion bodies may be abundant in some cases, in others they are few in number and difficult to find. In fact they have only been found in about 40 per cent. of cases as the result of a single examination. If, however, we take early primary cases, distinguishing them from relapses, then inclusion bodies will always be found, although it may be necessary to examine more 
than once. P.K.s may precede the clinical appearance of the disease (Taborisky, Wilson).

Characteristic free initial bodies of the bipolar bacillary type are not very common in films of Egyptian trachoma. It must, however, be realized that they are delicate objects and that a considerable proportion probably are destroyed or escape observation. Non-characteristic initial bodies such as small cocci, diplo- and

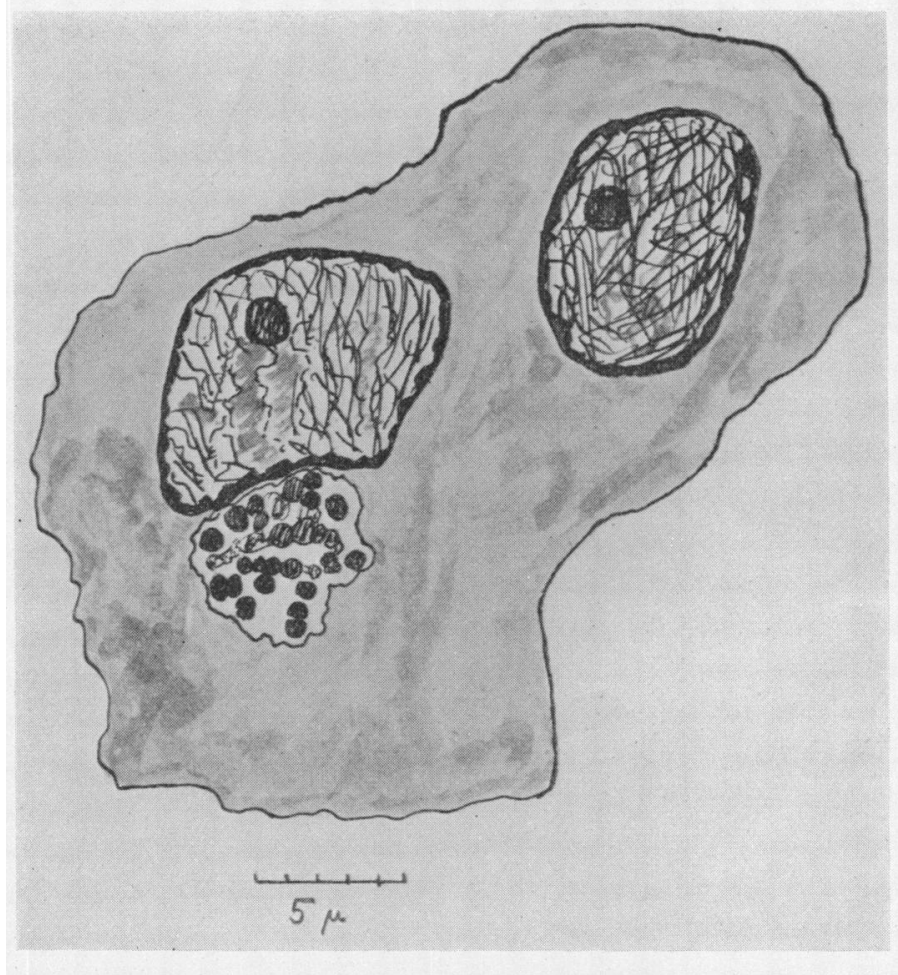

FIG. 2.

Epithelial cell with inclusion containing initial bodies.

coccobacilli abound. The intracellular initial body is the most common inclusion in trachoma.

Some authors have recently described the parasite of trachoma as a Rickettsia, grouping under this name the initial bodies and elementary granules with other more minute objects which are found in the follicles. The latter are probably cell detritus. Chlamydozoa differ from typical Rickettsiae such as R. Prowazeki in the following points, viz. the staining reaction of initial bodies is pure blue with Giemsa while Rickettsia stains purple, secondly the intracellular Rickettsia fills the cytoplasm of the host cell and 


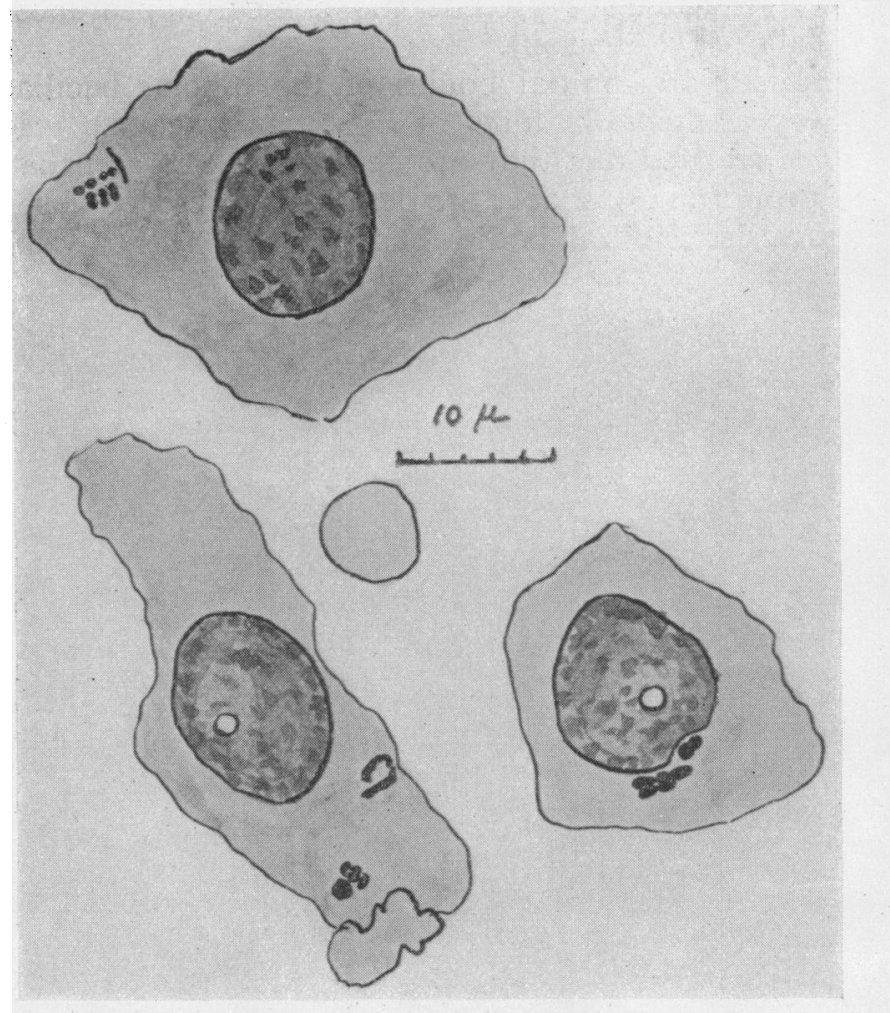

FIG. 3.

Three epithelial cells with initial body inclusions.

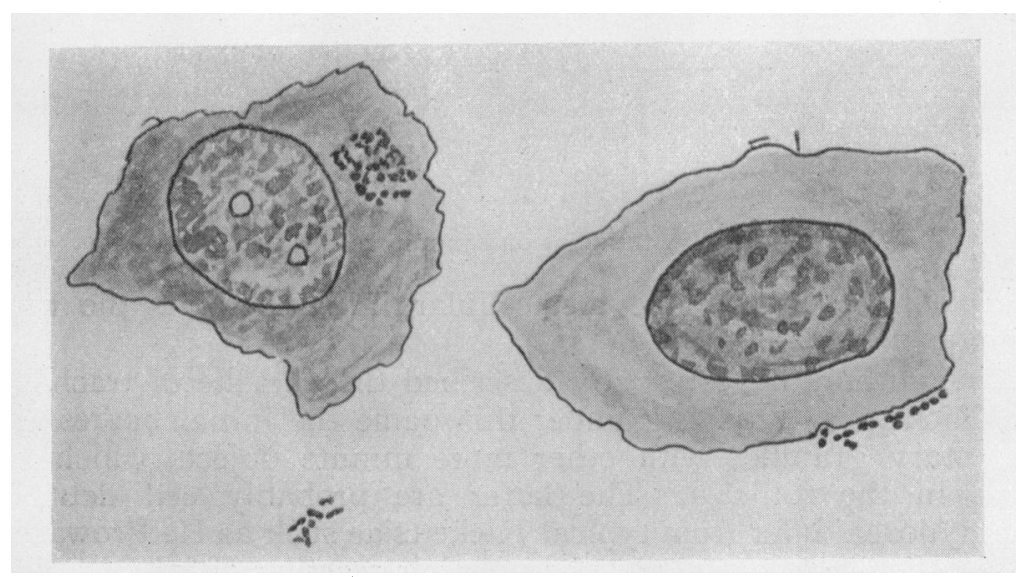

FIG. 4.

Two epithelial cells with free initial bodies (?), early intracellular initial bodies and Koch-Weeks bacilli. 


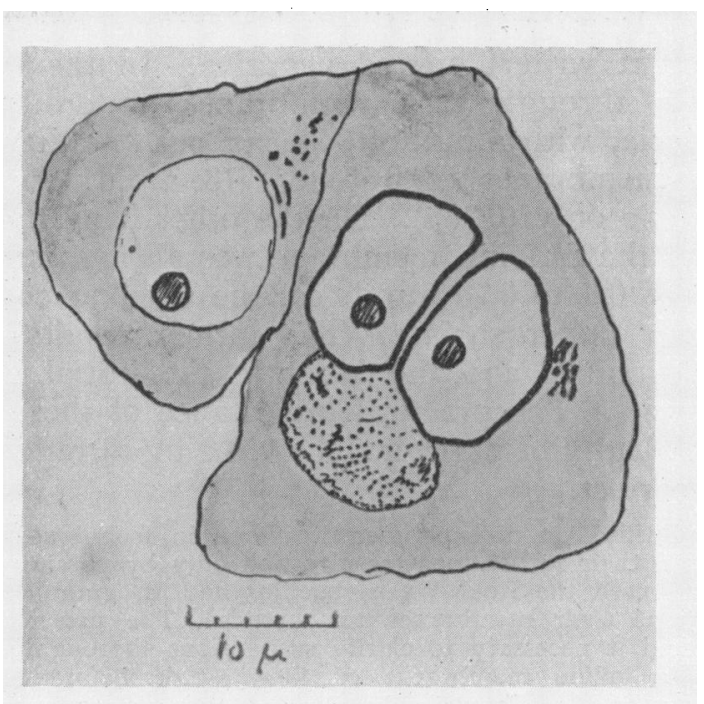

FIG. 5 .

Two conjunctival cells with small initial bodies, Koch-Weeks bacilli and a Prowazek - Halberstaedter body containing elementary granules.

is not restricted to a definite inclusion body and thirdly it has not been proved that Chlamydozoa either in trachoma, paratrachoma, psittacosis or granuloma inguinale are insect parasites.

The following objects have been mistaken at various times for Chlamydozoaazurophil granules of mononuclear leucocytes, granules of mast-cells, pigment granules of melanophores (cells which stain bright green with Giemsa). On the other hand free initial bodies have been mistaken for bacteria.

Allied Parasites.-Inclusion blennorrhoea of the new-born and swimming bath conjunctivitis (paratrachoma) are caused by a chlamydozoon indistinguishable from that of trachoma. Inclusion blennorrhoea has been recorded from Central Europe, Tunis, India and the United States. It is a remarkable fact that in Egypt blennorrhoea of any kind is exceedingly rare during the first month of life, while the inclusion variety has not been found at all.

The parasites of psittacosis and of granuloma inguinale resemble that of trachoma. They have a large form corresponding to the initial body and a small form to the elementary granules. The Paschen granules of vaccinia variola differ entirely in staining reaction from the granules of trachoma.

Filterability.-Recent experiments on the filtration of trachoma virus have given contradictory results. In one set of experiments in America (Thygeson and Proctor) the virus passed collodion membranes of 0.6 and $0.7 \mu$ average pore diameter and the filtrates caused infection in five mandrils and one human volunteer. A 
second set in America (Julianelle and Harrison) and one in Egypt (by the present writer) proved negative. In the last the virus passed freely through such membranes as are permeable to smaller bacteria, with a.p.d. of $0.8 \mu$ but out of thirty-four experiments with membranes of 0.55 to 0.73 a.p.d. the filtrate was infective in one only $(0.73 \mu)$. On the other hand the residue left on the top of the filtering membrane was always infective. Thus membranes of 0.6 to $0.7 \mu$ a.p.d. can be used to concentrate the virus on their upper surface. The former results point to the elementary granules and the latter to the initial bodies as the infecting agents. The practical importance of these experiments lies in the difficulty of purifying the virus by filtration if the latter results are correct.

The first and third set of experiments differed in technique. Thygeson and Proctor prepared their suspensions for filtration only by passing through a hard filter paper and used the Koch-Weeks bacillus and $B$. granulosis to prove the impermeability of their membranes to bacteria. The present writer on the other hand found it necessary to clarify suspensions thoroughly with sand and pulp or with collodion membranes of $1.0 \mu$ a.p.d. before filtering through 0.6 or $0.7 \mu$ membranes. Imperfectly clarified suspensions caused clogging of 0.6 or $0.7 \mu$ membranes and could not be filtered. He used B. prodigiosus as test bacterium.

Virulence of Trachoma.- It has been estimated by titration that the secretion of one trachomatous eyelid after filtration through sand and pulp is on the average able to infect between forty and three hundred eyes. Unfiltered material would of course be more potent. Comparing the suspensions used in the above filtration experiments with similar suspensions of vaccinia we find that the minimum infecting dose of trachoma is only slightly greater than that of commercial vaccinia and that therefore their virulence is approximately equal. Levaditi's neuro-testicular virus on the other hand is at least one hundred times as virulent.

Animals susceptible to trachoma.-Ordinary laboratory animals such as rabbits, guinea-pigs, cats and dogs cannot be infected in the conjunctiva. Among monkeys, baboons, grivets (Cercopithecus) and possibly mandrils are fully susceptible, an eruption of follicles covering the conjunctiva between fifteen and thirty -days after inoculation in every case. Chimpanzees, Barbary apes and macaques have given different results to different observers and cannot be relied on in more than 50 per cent. of experiments. P.K.s can rarely be found in the conjunctiva of infected monkeys. This is at least partly due to the greater delicacy of the epithelium of monkeys. Consequently P.K.S are larger, less compact and more easily destroyed than in man.

Guinea-pigs and rabbits injected in the testicle preserve the virus alive in that organ for some days or weeks. It is doubtful, however, whether the virus multiplies (Busacca, Julianelle, Cuénod and Nataf). If unfiltered trachoma emulsion is injected into the 
interior of the eyeball of rabbits or hens or into the meninges of guinea-pigs small lymphatic follicles appear in the choroid, retina or meninges, resembling the follicles of trachoma (v. Szily). Experimental proof by infection of monkeys has not been attempted.

Trachomatous material has been introduced into the tunica vaginalis of susceptible monkeys, baboons and grivets, and injected into the testicle, but the virus does not survive.

Attempts to grow the virus in tissue-culture have failed up to the present, while on the chorio-allantoic membrane of the hen's egg success has not been definitely proved.

Pandit, Wright and Rao (1935) recorded the appearance of lesions on the chorio-allantoic membrane after inoculation with unfiltered trachoma emulsion. The lesions could be propagated from egg to egg but did not cause infection when inoculated into the human conjunctiva (four persons inoculated). The authors therefore made no claim that the lesions were trachomatous.

Cuénod and Nataf in Paris inoculated eggs with material which had been sent frozen from Tunis by air-mail. They claim to have succeeded on the following grounds, viz. that an unusual number of the eggs died and that they found granules measuring $0.1 \mu$ in the membranes.

Carriage by Insects.-Lice injected per anum with a suspension of trachoma develop a pure culture of Rickettsia in the intestine (Cuénod and Nataf). The insects had been raised from the egg under experimental conditions and were free, with one exception, from spontaneous Rickettsia infection. Infected lice were ground up in a few drops of salt solution and instilled into the eyes of several Barbary apes and of one human volunteer, trachoma resulting. Material was collected from under the finger nails of a child suffering from trachoma and infested with lice. This material conveyed to the eye of a Barbarry ape caused trachoma. The authors believe that infection is spread normally in the excrement of infected lice. The above experiments were conducted in Tunis. In Cairo on the other hand large numbers of lice were collected from children with early trachoma, ground up in batches and instilled into the eyes of three baboons. Three hundred and seventy-nine body lice from ten children and one hundred and forty-three head lice from fifteen children were used but the baboons remained unaffected.

Flies.-In the Near East and other warm countries flies swarm around the eyes of children and feed on any discharge which may be present. They will obviously carry the virus of trachoma on legs and proboscis but only for a short time as the virus is killed by drying (Hess and Roemer). It is possible that flies also act as biological carriers. A series of experiments was carried out 
recently in Cairo in which flies after feeding on trachoma emulsion were killed after periods ranging from fifteen minutes to three days. The abdominal viscera, less ovaries or testes, were then ground in bouillon and rubbed into the eyelids of five baboons with negative results. The contents of the viscera were always acid and an acid reaction is promptly fatal to trachoma virus. It is possible that the reaction might be rendered neutral for a time by feeding the insects on flesh for some days and that the virus might so enter the salivary glands. Further experiments are needed.

\section{Summary}

Trachoma is caused by the virus described in 1907, the most conspicuous form of which is the Prowazek-Halberstaedter inclusion body or P.K. A free extracellular stage also exists resembling in appearance a polymorph bacterium. Inclusion bodies can be found in all cases of primary trachoma if examination is repeated. Allied diseases are paratrachoma (inclusion blennorrhoea and swimming bath conjunctivitis), psittacosis and granuloma inguinale, the parasites of which resemble that of trachoma. Reports on filtration through collodion membranes impermeable to bacteria, of 0.6 and $0.7 \mu$ a.p.d. are contradictory $(1)$ that the filtrate is infective $(2)$ that it is not so. The virus can be concentrated on the upper surface of such membranes. It has not been grown in any form of culture or on the chorio-allantoic membrane. Animals which can be infected with certainty in the conjunctiva are baboons and grivet monkeys. The virus can survive in the testicle of rabbits and guinea-pigs and it is claimed will multiply in the intestine of the louse. The statement that trachoma is normally carried by lice needs confirmation. There is some experimental evidence that it is not carried biologically by lice or flies. Infection is spread by direct contact and may be carried mechanically by cloths or by flies for a short time only since the virus is killed by drying.

\section{LITERATURE}

Busacca (1934).-Arch. f. Obhthal., Vol. CXXXIII p. 41.

CUÉNOD and NATAF (1936) -Arch. Inst. Pasteur, Tunis, Vol. XXV.p. 295 ; (1937) Ibid., Vol. XXVI, p. 1 ; (1938) Ibid., Vol. XXVII, p. 284.

Halberstaedter and Prowaze $(1907)$. -Arb.a.d. K. Gesundheitsamt, Berlin.

Hess and ROEMER (1906).-Arch.f. Augenheilk., Vol. LV, p. 3.

GreefF, Frosch and Clausen (1907). -Arch.f. Augenheilk., Vol. LVIII, p. 52 ; Ibid., Vol. LIX, p. 203.

JULIANELLE, MORRIS and HARRISON (1937).-Amer. Jl. Ophthal., Vol. XX, p. 890.

LINDNER (1909).-Zeitschr.f. Augenheilk., Vol. XXII, p. 547.

Pandit, Wright and Rao (1935).-Ind. Ji. of Med. Res, Vol. XXIII, p. 475.

Stewart (1938).-Ann. Rep. Mem. Ophthal. Lab., Giza.

TABORISKY (1930).-Arch. f. Ophthal., Vol. CXXIII, p 140.

ThYGeson and PROCTOR (1935).-Arch. of Ophthal., Vol. XIII, p. 1018 ; Amer. Jl. Ophthal., Vol. XVIII, p. 811.

Wilson (1938).-Ann. Rep. Mem. Ophthal. Lab., Giza, pp. 113 and 117. 